\title{
Identification of Anticoagulant Components in Korean Red Ginseng
}

\author{
Jae Joon Wee ${ }^{1}$, Young Sook Kim ${ }^{1}$, Jong Soo Kyung ${ }^{1}$, Yong Bum Song ${ }^{1}$, Jae Ho Do ${ }^{1}$, Dong Chung Kim², \\ and Sung Dong $\mathrm{Lee}^{3^{*}}$ \\ ${ }^{1}$ Ginseng Research Institute, Korea Ginseng Corporation, Daejeon 305-805, Korea \\ ${ }^{2}$ Department of Human Nutrition and Food Science, Chungwoon University, Hongseong 350-701, Korea \\ ${ }^{3}$ Department of Food and Nutrition, Korea University College of Health Science, Seoul 136-703, Korea
}

\begin{abstract}
In this study, the anticoagulant compounds in Korean red ginseng (KRG) were investigated. KRG powder was extracted using hot methanol, and the methanol extract was fractionated into $n$-hexane, ethylacetate, $n$-butanol, and aqueous fractions by solvent partitioning. The remains from the methanol extraction were further extracted with water and then dialyzed to obtain low and high molecular weight fractions. The anticoagulant activities of the seven fractions were evaluated in terms of thrombin time, prothrombin time, and activated partial thromboplastin time. Among these fractions, the ethylacetate fraction showed the most potent anticoagulant activity. The active components in the ethylacetate fraction were identified as the phenolic compounds vanillic, caffeic, ferulic, and $p$-coumaric acid via TLC and HPLC. These findings suggest that the anticoagulant activities of phenolic compounds contribute to the cardiovascular effects of KRG.
\end{abstract}

Keywords: Korean red ginseng, Anticoagulant activity, Phenolic compounds

\section{INTRODUCTION}

Ginseng is one of the most highly valued herbal medicines in Asian countries, including Korea, China, and Japan. It has also become a leading herbal supplement in Europe and the USA in recent years. Numerous studies have demonstrated the possible curative and restorative properties of ginseng in the treatment of cancer, diabetes, and neurodegenerative disease. Furthermore, there is increasing evidence of a role of ginseng in the cardiovascular system. Clinical trials have demonstrated certain beneficial effects of ginseng in patients with hypertension, atherosclerosis, and cardiac disorders.

Korean red ginseng (KRG, processed Panax ginseng C. A. Meyer) has been shown to significantly reduce the 24-h mean systolic blood pressure and improve vascular endothelial dysfunction in patients with essential hyper- tension $[1,2]$. KRG increased $\mathrm{PGI}_{2}$ formation in patients with atherosclerotic disorders and inhibited both ADPand collagen-induced platelet aggregation in healthy volunteers [3,4]. Epidemiological studies have demonstrated that the long-term intake of ginseng significantly prolonged plasma clotting times $[5,6]$. Both in vitro and in vivo studies have indicated that ginsenosides, the active components in ginseng, have potential cardiovascular benefits. These effects have been shown to be due to vasorelaxation, effects on ion channels, decreased cardiac contraction, reduced platelet aggregation, fibrinolysis, improved lipid profiles, and regulation of the glycemic index.

Kim et al. [7] studied the effect of ginsenosides on the release of nitric oxide (NO) from endothelial cells and

(c) This is an Open Access article distributed under the terms of the Creative Commons Attribution Non-Commercial License (http://creativecommons.org/licenses/by-nc/3.0/) which permits unrestricted non-commercial use, distribution, and reproduction in any medium, provided the original work is properly cited.

Received 20 Aug. 2010, Revised 19 Nov. 2010, Accepted 20 Nov. 2010

*Corresponding author

E-mail: 1sdojm@hanmail.net

Tel: +82-2-940-2851, Fax: +82-2-915-5704 
discovered that the ginsenoside $\operatorname{Rg}_{3}$ was the most potent vasodilator among all of the ginsenosides examined. $\mathrm{Rg}_{3}$-induced endothelium-dependent relaxation was markedly inhibited by tetraethylammonium, a non-selective $\mathrm{K}^{+}$channel blocker, suggesting that $\mathrm{Rg}_{3}$ activates tetraethylammonium-sensitive $\mathrm{K}^{+}$channels in endothelial cells to promote $\mathrm{Ca}^{++}$influx and the subsequent activation of endothelial NO synthase [8]. In contrast, Chen [9] examined the relaxation of pulmonary vessels in response to the ginsenosides $\mathrm{Rb}_{1}$ and $\mathrm{Rg}_{1} . \mathrm{Rb}_{1}$ and Re decreased the contraction of adult rat ventricular myocytes [10], while ginsenosides $R b_{1}, \mathrm{Rb}_{2}$, and $\mathrm{Rb}_{3}$ inhibited the contractility of normal myocardial cells [11]. Furthermore, $\operatorname{Rg}_{1}$ exhibited potent anti-aggregatory activity in vitro when platelets were stimulated with collagen and arachidonic acid [12], and $\mathrm{Rg}_{3}$ and its derivatives were shown to be potent antagonists of $\left[{ }^{3} \mathrm{H}\right]$-platelet activating factor [13]. Further, $\mathrm{Rb}_{2}$ enhanced the fibrinolytic activity of bovine aortic endothelial cells [14]. In contrast, the hypolipidemic effects of ginseng saponins were examined in rats fed a high-fat diet and in cyclophosphamideinduced hyperlipidemic rabbits $[15,16]$. Yokozawa et al. [17] demonstrated the hyperlipidemia-improving and hypoglycemic effects of $\mathrm{Rb}_{2}$ on streptozotocin-induced diabetic rats.

As described above, the ginsenosides involved in cardiovascular pharmacology (e.g., vasorelaxation, antiplatelet aggregation, hypolipidemia, and hypoglycemia) have been studied extensively, whereas other components of KRG have not been fully explored. Many epidemiological studies have shown protective effects of plant-based diets on cardiovascular disease, leading to the discovery of various bioactive compounds, including phenolic compounds, phytoestrogens, carotenoids, organosulfur compounds, and monoterpenes. Many phenolic compounds have antioxidative properties, and some studies have demonstrated favorable effects on thrombosis [18]. Thus, we searched for novel active compounds in KRG using an anticoagulation assay system. Through the screening of various fractions of $\mathrm{KRG}$, we found that the ethylacetate (EtOAc) fraction possessed potent anticoagulant activity in vitro, and phenolic acids were identified as the active components in this fraction.

\section{MATERIALS AND METHODS}

\section{Materials}

KRG powder (Jungkwanjang) was provided by Korea Ginseng Corporation (Daejeon, Korea). Citrated human plasma was obtained from the Red Cross Blood Center (Daejeon, Korea). Thromboplastin, bovine thrombin, and authentic phenolic compounds were purchased from Sigma Chemical Co. (St. Louis, MO, USA). TLC plates were obtained from Merck (Darmstadt, Germany). HPLC columns and the packing material for reverse-phase column chromatography were purchased from YMC Co. (Kyoto, Japan). All other chemicals were of analytical grade.

\section{Extraction and fractionation}

KRG powder $(100 \mathrm{~g})$ was extracted with $500 \mathrm{~mL}$ of hot methanol $(\mathrm{MeOH})$ four times. The $\mathrm{MeOH}$ extract was pooled and concentrated. Next, the $\mathrm{MeOH}$ extract was dissolved in distilled water and fractionated by solvent partitioning (Fig. 1) to produce $n$-hexane, ethylacetate (EtOAc), $n$-butanol $(\mathrm{BuOH})$, and aqueous fractions; the yields were $0.43,1.90,10.63$, and $22.32 \%$, respectively. The residue remaining from the $\mathrm{MeOH}$ extraction was further extracted with water. The water extract was dialyzed against tap water for two days, and the resultant inner portion was precipitated with ethanol to obtain low and high molecular fractions (Fig. 1). The lipophilic fraction was dissolved in 10\% dimethylsulfoxide; all others were dissolved in distilled water before use.

\section{Anticoagulation assay}

To screen the fractions for anticoagulant activity, the clotting times were measured using a blood coagulation analyzer (Behnk Elektronik, Norderstedt, Germany). To measure the thrombin time (TT), $50 \mu \mathrm{L}$ of $0.02 \mathrm{M}$ $\mathrm{CaCl}_{2}, 50 \mu \mathrm{L}$ of thrombin, and $50 \mu \mathrm{L}$ of each fraction were preincubated at $37^{\circ} \mathrm{C}$ for 3 minutes. The coagulation reaction was started by the addition of $100 \mu \mathrm{L}$ of citrated human plasma. The prothrombin time (PT) was measured by the preincubation of $100 \mu \mathrm{L}$ of human plasma with $50 \mu \mathrm{L}$ of each fraction, followed by the addition of $100 \mu \mathrm{L}$ of thromboplastin-D. To measure the activated partial thromboplastin time (aPTT), $100 \mu \mathrm{L}$ of human plasma, $100 \mu \mathrm{L}$ of aPTT-XL, and $50 \mu \mathrm{L}$ of each fraction were preincubated at $37^{\circ} \mathrm{C}$ for 3 minutes, after which $100 \mu \mathrm{L}$ of $0.02 \mathrm{M} \mathrm{CaCl}_{2}$ were added to start the coagulation reaction.

\section{Column chromatography and preparative HPLC}

The anticoagulant-active EtOAc fraction was further fractionated by reverse-phase column chromatography. Briefly, the EtOAc fraction was passed through a $\mathrm{C}_{18}$ glass column $(\Phi 15 \times 150 \mathrm{~mm}, 75 \mu \mathrm{m})$ to obtain subfractions. The column was eluted with $50 \% \mathrm{MeOH}$ followed 


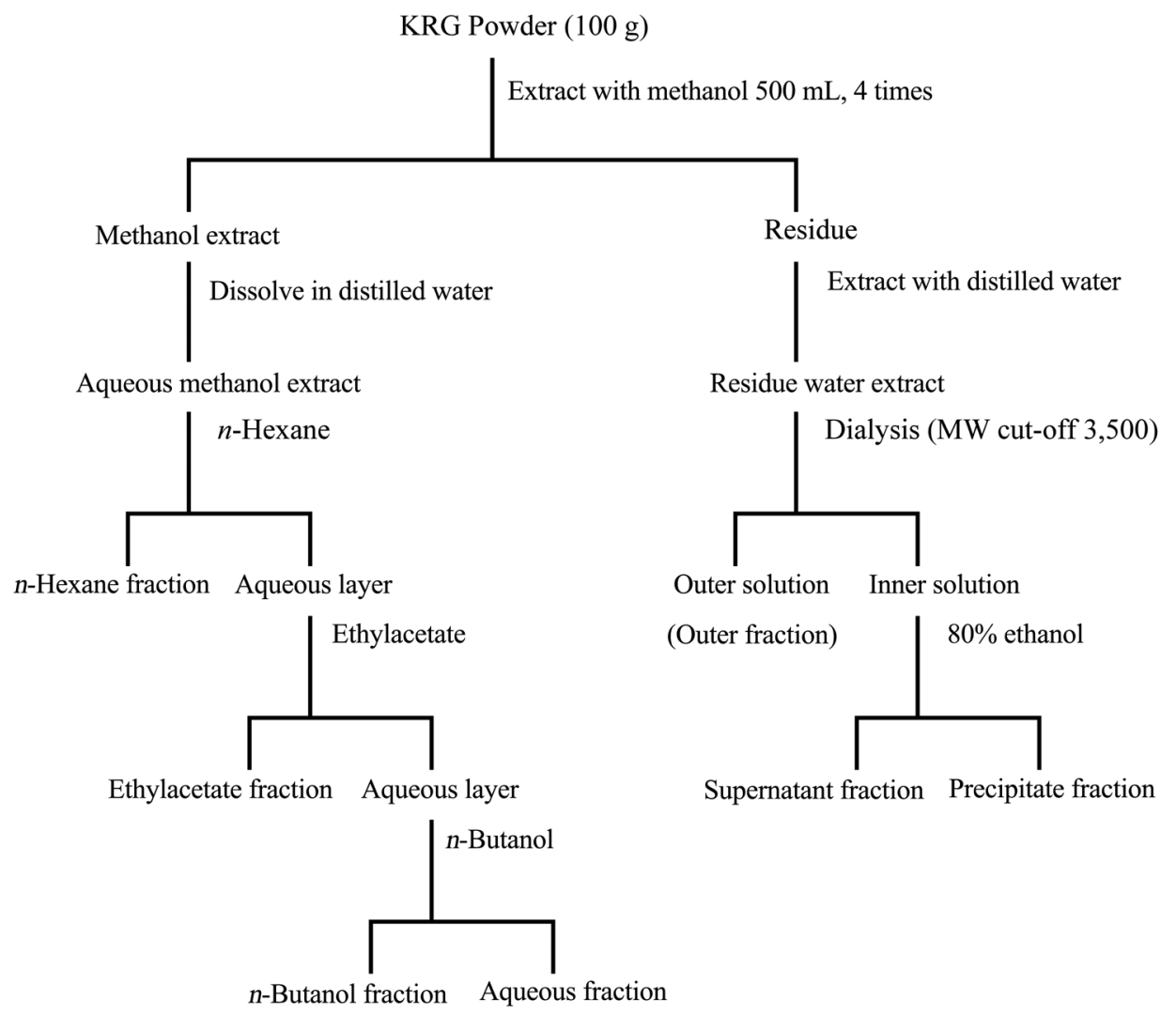

Fig. 1. Extraction and fractionation of the constituents in Korean red ginseng. MW, molecular weight.

by $100 \% \mathrm{MeOH}$. The subfractions were assayed for anticoagulant activity. The $50 \% \mathrm{MeOH}$ subfraction was further subjected to HPLC using a $\mathrm{C}_{18}$ column $(\Phi 20 \times 250 \mathrm{~mm}, 10 \mu \mathrm{m})$ and $\mathrm{CH}_{3} \mathrm{CN} / \mathrm{H}_{2} \mathrm{O} /$ phosphoric acid (20:80:0.2, v/v) mobile phase at a flow rate of 2 $\mathrm{mL} / \mathrm{min}$. The $n-\mathrm{BuOH}$ fraction was chromatographed on a silica gel (70-230 mesh) column with $\mathrm{CHCl}_{3} / \mathrm{MeOH} /$ $\mathrm{H}_{2} \mathrm{O}$ as a developing solvent to separate the saponins protopanaxadiol (PPD) and protopanaxatriol (PPT).

\section{TLC}

Silica gel TLC was performed to identify the active components. The plate was developed with $\mathrm{CHCl}_{3} /$ $\mathrm{MeOH} / \mathrm{H}_{2} \mathrm{O}(65: 35: 10, \mathrm{v} / \mathrm{v}), 0.5 \% \mathrm{FeCl}_{3}$ in $0.1 \mathrm{~N} \mathrm{HCl}$ was sprayed to detect phenolic compounds.

\section{Analytical HPLC}

The EtOAc fraction and its subfractions were analyzed by HPLC (Waters Corp., Milford, MA, USA) using a $\mathrm{C}_{18}$ column $(\Phi 4.6 \times 250 \mathrm{~mm}, 5 \mu \mathrm{m})$ to detect ginsenosides or phenolic compounds. The mobile phase was a $\mathrm{CH}_{3} \mathrm{CN} / \mathrm{H}_{2} \mathrm{O}$ gradient for ginsenosides, and $\mathrm{CH}_{3} \mathrm{CN} /$ $\mathrm{H}_{2} \mathrm{O} /$ phosphoric acid (8:92:0.2, v/v) for phenolic com- pounds, respectively. The detection wavelength was $203 \mathrm{~nm}$ for ginsenosides and $310 \mathrm{~nm}$ for phenolic compounds, respectively.

\section{RESULTS AND DISCUSSION}

\section{Effect of the Korean red ginseng extract fractions on blood coagulation}

Seven fractions obtained by the fractionation of a KRG MeOH extract were evaluated for their anticoagulation activity. Among them, only the EtOAc fraction prolonged clotting time markedly, as measured by the TT (Table 1). Based on this result, the EtOAc fraction was used to isolate anticoagulant-active components. The EtOAc fraction was further fractionated by reversephase column chromatography to yield subfractions $(50 \%$ and $100 \% \mathrm{MeOH})$. The $50 \% \mathrm{MeOH}$ subfraction showed remarkably potent inhibitory activity against blood coagulation compared to the $100 \% \mathrm{MeOH}$ subfraction (Table 2). Generally, the EtOAc fraction is used to isolate less polar ginsenosides, including $\mathrm{Rh}_{1}, \mathrm{Rh}_{2}$, $\mathrm{Rg}_{1}$, and $\mathrm{Rg}_{3}$. Therefore, we analyzed the $50 \% \mathrm{MeOH}$ subfraction by HPLC to examine whether these ginsen- 
Table 1. Effect of various fractions prepared from Korean red ginseng methanol extract on thrombin time

\begin{tabular}{cccccc}
\hline \multirow{2}{*}{ Fractions } & \multicolumn{5}{c}{ Thrombin time (s) } \\
\cline { 2 - 6 } & 5.0 & 2.5 & 1.25 & 0.625 & 0.3125 \\
\cline { 2 - 6 }$n$-Hexane & 18.1 & - & - & - & - \\
Ethylacetate & $>200$ & $>200$ & 111.3 & 55.2 & 23.2 \\
$n$-Butanol & 23.7 & - & - & - & - \\
Aqueous & 27.4 & - & - & - & - \\
Outer & 32.6 & - & - & - & - \\
Inner-supernatant & 27.2 & - & - & - & - \\
Inner-precipitate & 22.1 & - & - & - & - \\
\hline
\end{tabular}

Each value represents the average of duplicate experiments. Each fraction was dissolved in $10 \%$ dimethylsulfoxide or distilled water at a concentration of $25 \mathrm{mg} / \mathrm{mL}$. osides were present. The HPLC traces revealed that $\mathrm{Rg}_{1}$, $\mathrm{Rf}, \mathrm{Rh}_{1}$, and $\mathrm{Rg}_{3}$, which appeared in the EtOAc fraction, were weakly detected in the anticoagulant-active 50\% $\mathrm{MeOH}$ subfraction (Fig. 2). This result indicates that saponins do not contribute to the anticoagulation activity of the EtOAc fraction. To confirm this, we prepared PPD and PPT saponin fractions, and examined their anticoagulation activities (Table 3). As shown in Table 3, the PPD and PPT fractions did not show anticoagulation activity. The $50 \% \mathrm{MeOH}$ subfraction was further separated using preparative HPLC to give fractions $1-4$, in order of elution. Fractions 2 and 3 showed potent anticoagulation activity (data not shown). The anticoagulantactive components in fraction 2 and 3 were studied chromatographically.

Table 2. Effect of subfractions derived from the ethylacetate fraction on plasma clotting times

\begin{tabular}{cccc}
\hline \multirow{2}{*}{ Subfractions } & \multicolumn{3}{c}{ Clotting time (s) } \\
\cline { 2 - 4 } & Thrombin time & Prothrombin time & Activated partial thromboplastin time \\
\hline $50 \%$ methanol & $>200$ & $>200$ & 76.8 \\
$100 \%$ methanol & 22.4 & 35.5 & 26.2 \\
\hline
\end{tabular}

Each value represents the average of duplicate experiments.

${ }^{1)}$ Subfractions were obtained by reverse-phase column chromatography of the ethylacetate fraction and dissolved in $10 \%$ dimethylsulfoxide at a concentration of $25 \mathrm{mg} / \mathrm{mL}$.
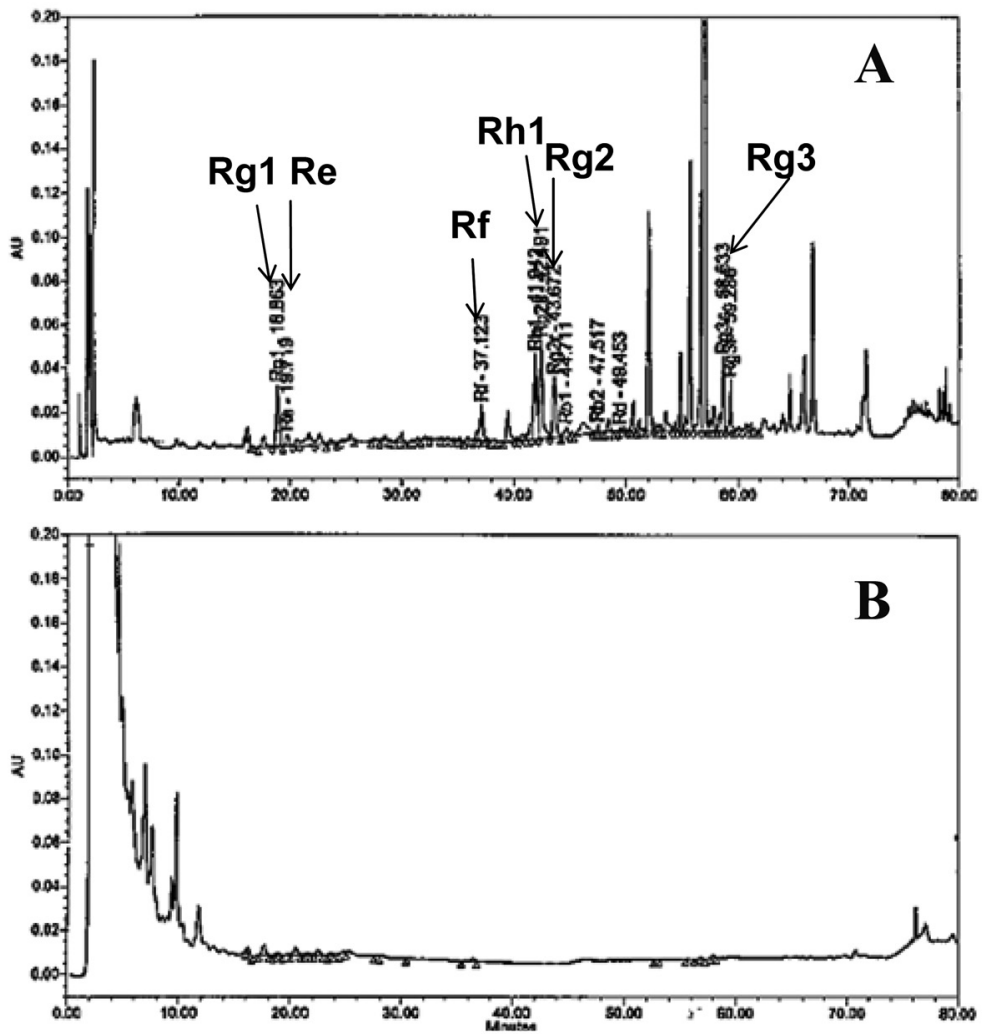

Fig. 2. HPLC chromatograms of the ethylacetate (EtOAc) fraction and its subfraction. (A) Korean red ginseng EtOAc fraction. (B) $50 \%$ methanol subfraction. Column, $\mathrm{C}_{18}(\Phi 4.6 \times 250 \mathrm{~mm}, 5 \mu \mathrm{m})$; mobile phase, $\mathrm{CH}_{3} \mathrm{CN} / \mathrm{H}_{2} \mathrm{O}$ gradient; flow rate, $1 \mathrm{~mL} / \mathrm{min}$; detection wavelength, $203 \mathrm{~nm}$; $\mathrm{AU}$, absorption unit. 
Table 3. Effects of saponin fractions on thrombin time

\begin{tabular}{cccc}
\hline \multirow{2}{*}{ Saponin fractions ${ }^{1)}$} & \multicolumn{3}{c}{ Thrombin time $(\mathrm{s})$} \\
\cline { 2 - 4 } & \multicolumn{3}{c}{ Final concentration $(\mathrm{mg} / \mathrm{mL})$} \\
\cline { 2 - 4 } & 5.0 & 2.0 & 1.0 \\
\hline Protopanaxadiol saponin fraction & 16.9 & - & - \\
Protopanaxatriol saponin fraction & 16.6 & - & - \\
Aspirin & $>200$ & 104.4 & 27.6 \\
\hline
\end{tabular}

Each value represents the average of duplicate experiments.

${ }^{1)}$ Protopanaxadiol and protopanaxatriol saponin fractions were prepared from the $n$-butanol fraction by silica gel column chromatography.

\section{Identification of phenolic components and their anticoagulant activity}

Maltol was identified in fr. 2 by TLC based on the $\mathrm{R}_{\mathrm{f}}$ value and $\mathrm{FeCl}_{3}$ color reaction (Fig. 3); this was confirmed by HPLC (Fig. 4). Additionally, protocatechuic acid was identified in fr. 2, while $p$-hydroxybenzoic, vanillic, caffeic, $p$-coumaric, and ferulic acid were identified in fr. 3 by HPLC (Fig. 4). $p$-Coumaric, ferulic, caffeic, vanillic, and protocatechuic acid, but not maltol, had potent inhibitory effects on blood coagulation, as shown by the TT (Table 4).

Blood coagulation and platelet aggregation are crucial events in thrombosis, which is a major cause of human mortality. When a blood vessel is injured, both the intrinsic and extrinsic coagulation pathways become activated, leading to the formation of blood clots to minimize blood loss. Problems with this process can result in the formation of an excessive number of platelet/fibrin-

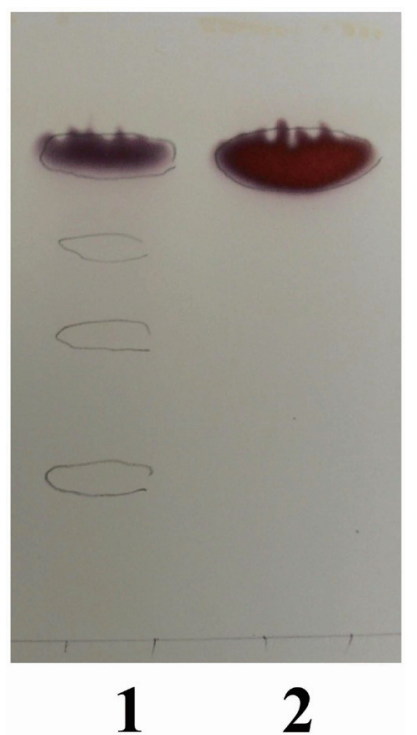

Fig. 3. TLC chromatogram of fraction 2. Lane 1, fraction 2; lane 2, maltol standard; plate, silica gel 60 pre-coated aluminum sheet, layer thickness $0.2 \mathrm{~mm}$; solvent system, $\mathrm{CHCl}_{3} / \mathrm{MeOH} / \mathrm{H}_{2} \mathrm{O}(65: 35: 10$, v/v); detection, $\mathrm{FeCl}_{3}$ spray.

rich thrombi, which obstruct blood flow in the circulatory system. In a recent report, Jin et al. [19] showed that the administration of KRG extract to rats prevented carotid arterial thrombosis in vivo, whereas it failed to prolong coagulation times ex vivo. They concluded that the antithrombotic effect of KRG extract might not be due to its anticoagulation effect, but rather to antiplatelet aggregation activity. Nonetheless, Matsuda and Kubo [20] reported that a $70 \% \mathrm{MeOH}$ extract of $\mathrm{KRG}$ prevented the disruption of the intravascular coagulative system

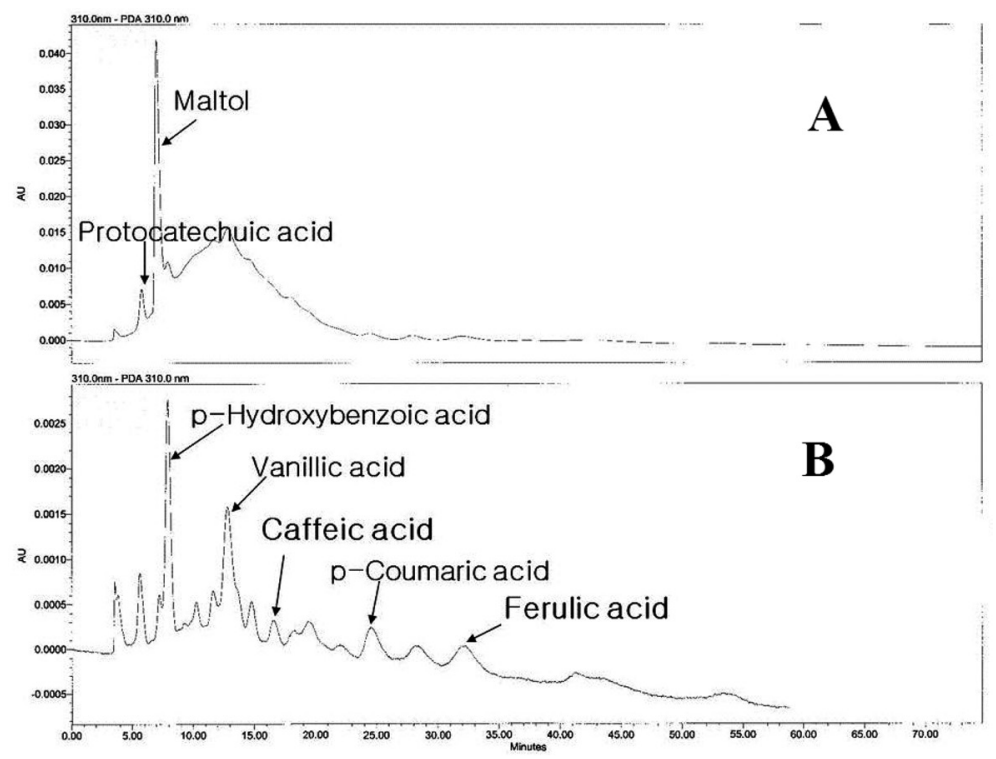

Fig. 4. HPLC chromatograms of fractions 2 and 3. (A) fraction 2. (B) fraction 3. Column, $\mu$-Bondapak $\mathrm{C}_{18}(\Phi 3.9 \times 300 \mathrm{~mm}, 5 \mu \mathrm{m})$; mobile phase, $\mathrm{CH}_{3} \mathrm{CN} / \mathrm{H}_{2} \mathrm{O} /$ phosphoric acid $(8: 92: 0.2, \mathrm{v} / \mathrm{v})$; flow rate, $1 \mathrm{~mL} / \mathrm{min}$; detection wavelength, $310 \mathrm{~nm} ; \mathrm{AU}$, absorption unit. 
Table 4. Anticoagulant activity of phenolic compounds identified in the ethylacetate fraction prepared from Korean red ginseng methanol extract

\begin{tabular}{ccccc}
\hline & \multicolumn{3}{c}{ Thrombin time $(\mathrm{s})$} & \multirow{2}{*}{ Remark } \\
\cline { 2 - 4 } Phenolic compounds & 5.0 & Final concentration $(\mathrm{mg} / \mathrm{mL})$ & 0.5 \\
\cline { 2 - 4 } & $>200$ & 2.5 & $27.0^{*}$ & Cinnamic acid derivative \\
\cline { 2 - 4 }$p$-Coumaric acid & $>200$ & $>200$ & 24.3 & Cinnamic acid derivative \\
Ferulic acid & $>200$ & $>200$ & 26.9 & Cinnamic acid derivative \\
Caffeic acid & $>200$ & $>200$ & 26.5 & Benzoic acid derivative \\
Vanillic acid & $>200$ & $>200$ & 21.6 & Benzoic acid derivative \\
Protocatechuic acid & 34.7 & 23.5 & 17.4 & - \\
Maltol & & &
\end{tabular}

Each value represents the average of duplicate experiments. Each phenolic compound was dissolved in methanol.

induced by endotoxin and thrombin in rats. Also, KRG significantly prolonged the aPTT and PT in a blood stasis rat model [21]. Furthermore, an antithrombin-active polysaccharide with an inhibitory effect on blood coagulation has been isolated from KRG [22].

In the present study, we employed a systematic fractionation method to search for the anticoagulant-active components in KRG. Among seven fractions obtained from a $\mathrm{MeOH}$ extract of $\mathrm{KRG}$ powder, only the EtOAc fraction showed potent anticoagulant activity, whereas the other fractions showed almost no such activity (Table $1)$. The fact that the $n$-hexane and $n-\mathrm{BuOH}$ fractions showed no activity implies that non-polar fat-soluble compounds such as polyacetylenes and ginsenosides do not possess anticoagulant activity. In addition, the inner precipitate portion of the dialysis (a polysaccharide fraction), showed no anticoagulant activity, suggesting that this fraction did not contain the antithrombin-active polysaccharide isolated by Kim et al. [22]. Further fractionation of the EtOAc fraction by reverse-phase column chromatography afforded a remarkably potent<smiles>[R6]c1c(Br)cc(C(=O)O)cc1Br</smiles>

Benzoic acid derivates

\section{R1 R2 R3 \\ $\mathrm{H} \quad \mathrm{OH} \quad \mathrm{H} \quad$ p-Hydroxybenzoic acid $\mathrm{H}$ $\mathrm{OH} \mathrm{OH}$ H Protocatechuic acid $\mathrm{H} \quad \mathrm{OH} \quad \mathrm{OCH} 3$ Vanillic acid}

anticoagulative subfraction (50\% $\mathrm{MeOH}$ subfraction) (Table 2). The HPLC trace of the $50 \% \mathrm{MeOH}$ subfraction indicated no ginsenosides, revealing that ginsenosides are excluded from these active components (Fig. $2)$. Finally, the phenolic acids $p$-coumaric, ferulic, caffeic, vanillic, and protocatechuic acid were identified in the active subfractions of fractions 2 and 3 by HPLC, implying that phenolic acids are anticoagulant-active compounds (Fig. 4). In fact, the phenolic acids in the EtOAc fraction showed strong anticoagulant activity in vitro, suggesting that phenolic acids contribute to the cardiovascular effects of KRG (Table 4). The chemical structures of these phenolic acids are illustrated in Fig. 5. As shown, hydroxybenzoic acid is based on a C6-C1 skeleton. Cinnamic acids are a series of trans-phenyl-3propenoic acids with $\mathrm{C} 6-\mathrm{C} 3$ structures that differ in their ring substitutions. Caffeic acid, its esters, and ferulic acid are the most frequently encountered phenolic acids in plant foods. Phenolic acids constitute one of several categories of plant-derived phenolic compounds, including flavones, flavonols, isoflavones, anthocyanidins, fla-<smiles>[R]c1cc(C=CC(=O)O)cc([18OH])c1[R]</smiles>

Cinnamic acid derivates

R4 R5 R6

Fig. 5. Chemical structures of the phenolic acids in Korean red ginseng. 
vanols, flavanones, tannins, stilbenes, and lignans. Phenolic compounds have received an increasing amount of attention because of their antioxidative properties, which may help prevent cardiovascular disease. For example, green tea catechin has antithrombotic activity in rats, while $p$-coumaric acid has antiplatelet activity in rabbits $[23,24]$.

Many natural products have potential benefits in the prevention and treatment of cardiovascular disorders, including citrus fruits, tea, coffee, ginkgo, tomato, grape, red wine, olive oil, fish oil, and soy. The bioactive compounds in these products include flavonoids, lycopene, resveratrol, omega-3 fatty acids, and isoflavone, as well as natural antioxidative nutrients such as ascorbate (vitamin C), tocopherols (vitamin E), and carotenoids. Epidemiological and clinical studies have shown that these natural products can reduce cardiovascular risk factors, including blood pressure, plasma lipids, blood coagulation, and platelet aggregation. Panax ginseng has also been studied extensively for its cardiovascular effects, and many experimental studies have demonstrated that ginsenosides, particularly $\mathrm{Rg}_{3}$, are active in vasorelaxation. However, in this study, we found that ginsenosides were inactive against blood coagulation, whereas phenolic acids were active, suggesting that they exert their cardiovascular effects through different mechanisms. On the other hand, it is unknown whether this effect occurs at the concentrations found in blood following the ingestion of ginseng products at the recommended doses, particularly considering that the content of total phenolic acids is around $0.01 \%$, which is far less than that of ginsenosides [25].

In conclusion, the phenolic compounds in KRG have potent anticoagulant activity, whereas the saponin fractions, which were previously shown to possess antiplatelet aggregation activity, do not. Taken together, these results suggest that both saponins and phenolic compounds contribute to the cardiovascular effects of KRG through their antiplatelet aggregation and anticoagulant activities, respectively. Additional in vivo studies of the anticoagulant activities of phenolic compounds will be useful to better understand the pharmacology of these compounds.

\section{REFERENCES}

1. Han KH, Choe SC, Kim HS, Sohn DW, Nam KY, Oh BH, Lee MM, Park YB, Choi YS, Seo JD, et al. Effect of red ginseng on blood pressure in patients with essential hypertension and white coat hypertension. Am J Chin Med
1998;26:199-209.

2. Sung J, Han KH, Zo JH, Park HJ, Kim CH, Oh BH. Effects of red ginseng upon vascular endothelial function in patients with essential hypertension. Am J Chin Med 2000;28:205-216.

3. Hirai A. Studies on the mechanisms of anti-platelet and antiatherosclerotic effects of the Korean red ginseng: focusing on arachidonic acid cascade. In: Proceedings of ' 99 KoreaJapan Ginseng Symposium; 1999 Sept 30; Seoul, Korea; 1999. p.16-31.

4. Shin KS, Lee JJ, Kim YI, Yu JY, Park ES, Im JH, You $\mathrm{SH}$, Oh KW, Lee MK, Wee JJ, et al. Effect of Korean red ginseng extract on blood circulation in healthy volunteers: a randomized, double-blind, placebo-controlled trial. J Ginseng Res 2007;31:109-116.

5. Lee JH, Kim SH. The effect of the long-term ginseng intakes on serum lipids profile and hemostatic factors in human. Korean J Nutr 1995;28:862-871.

6. Lee JH, Park HJ. Effects of intaking of red ginseng products on human platelet aggregation and blood lipids. J Ginseng Res 1998;22:173-180.

7. Kim ND, Kim EM, Kang KW, Cho MK, Choi SY, Kim SG. Ginsenoside $\mathrm{Rg}_{3}$ inhibits phenylephrine-induced vascular contraction through induction of nitric oxide synthase. Br J Pharmacol 2003;140:661-670.

8. Kim ND, Kang SY, Park JH, Schini-Kerth VB. Ginsenoside $\mathrm{Rg}_{3}$ mediates endothelium-dependent relaxation in response to ginsenosides in rat aorta: role of $\mathrm{K}+$ channels. Eur J Pharmacol 1999;367:41-49.

9. Chen X. Cardiovascular protection by ginsenosides and their nitric oxide releasing action. Clin Exp Pharmacol Physiol 1996;23:728-732.

10. Scott GI, Colligan PB, Ren BH, Ren J. Ginsenosides $\mathrm{Rb}_{1}$ and Re decrease cardiac contraction in adult rat ventricular myocytes: role of nitric oxide. Br J Pharmacol 2001; 134:1159-1165.

11. Jiang Y, Zhong GG, Chen L, Ma XY. Influences of ginsenosides $\mathrm{Rb}_{1}, \mathrm{Rb}_{2}$, and $\mathrm{Rb}_{3}$ on electric and contractile activities of normal and damaged cultured myocardiocytes. Zhongguo Yao Li Xue Bao 1992;13:403-406.

12. Yamamoto K, Hirai A, Tamura Y, Yoshida S. In vitro and in vivo effect of ginseng saponins, major components of Korean red ginseng on human platelet aggregation and archidonic acid metabolism. J Tradit Med 1988;5:184-190.

13. Jung KY, Kim DS, Oh SR, Lee IS, Lee JJ, Park JD, Kim SI, Lee HK. Platelet activating factor antagonist activity of ginsenosides. Biol Pharm Bull 1998;21:79-80.

14. Liu JW, Wei DZ, Du CB, Zhong JJ. Enhancement of fibrinolytic activity of bovine aortic endothelial cells by ginsenoside $\mathrm{Rb}_{2}$. Acta Pharmacol Sin 2003;24:102-108. 
15. Ikehara M, Shibata Y, Higashi T, Sanada S, Shoji J. Effect of ginseng saponins on cholesterol metabolism. III. Effect of ginsenoside- $\mathrm{Rb}$ on cholesterol synthesis in rats fed on highfat diet. Chem Pharm Bull (Tokyo) 1978;26:2844-2854.

16. Inoue M, Wu CZ, Dou DQ, Chen YJ, Ogihara Y. Lipoprotein lipase activation by red ginseng saponins in hyperlipidemia model animals. Phytomedicine 1999;6:257-265.

17. Yokozawa T, Kobayashi T, Oura H, Kawashima Y. Stimulation of lipid and sugar metabolism in ginsenoside- $\mathrm{Rb}_{2}$ treated rats. Chem Pharm Bull (Tokyo) 1984;32:27662772.

18. Kris-Etherton PM, Hecker KD, Bonanome A, Coval SM, Binkoski AE, Hilpert KF, Griel AE, Etherton TD. Bioactive compounds in foods: their role in the prevention of cardiovascular disease and cancer. Am J Med 2002;113 Suppl 9B:71S-88S

19. Jin YR, Yu JY, Lee JJ, You SH, Chung JH, Noh JY, Im JH, Han XH, Kim TJ, Shin KS, et al. Antithrombotic and antiplatelet activities of Korean red ginseng extract. Basic Clin Pharmacol Toxicol 2007;100:170-175.

20. Matsuda H, Kubo M. Pharmacological study on Panax ginseng C.A. Meyer. I. Effects of red ginseng on the experi- mental disseminated intravascular coagulation. Yakugaku Zasshi 1983;103:1269-1277.

21. Yun YP, Do JH, Ko SR, Ryu SY, Kim JH, Song HC, Park YD, Ahn KS, Kim SH. Effects of Korean red ginseng and its mixed prescription on the high molecular weight dextran-induced blood stasis in rats and human platelet aggregation. J Ethnopharmacol 2001;77:259-264.

22. Kim DC, In MJ, Lee JY, Hwang YK, Lee SD. Antithrombin active polysaccharide isolated from the alkaline extract of red ginseng. J Ginseng Res 1999;23:217-221.

23. Kang WS, Lim IH, Yuk DY, Chung KH, Park JB, Yoo HS, Yun YP. Antithrombotic activities of green tea catechins and (-)-epigallocatechin gallate. Thromb Res 1999;96:229237.

24. Luceri C, Giannini L, Lodovici M, Antonucci E, Abbate R, Masini E, Dolara P. p-Coumaric acid, a common dietary phenol, inhibits platelet activity in vitro and in vivo. Br J Nutr 2007;97:458-463.

25. Park MK, Park JH, Kim KH, Han SB, Han BH. Analysis of aromatic acids in Panax ginseng by gas chromatography. Yakhak Hoeji 1994;38:389-393. 